\title{
20 ANOS DA REVISTA DE DIREITO SANITÁRIO: MOMENTO DE RENOVAÇÃO
}

Há 20 anos, nascia a Revista de Direito Sanitário, gestada com maior ou menor entusiasmo nos 10 anos anteriores. Naquela época, éramos ainda um pequeno grupo de estudiosos do tema, predominantemente com inserção prioritária nos serviços de saúde e na universidade. Sabíamos que o crescimento do grupo recomendava um foro para a discussão acadêmica das complexas questões envolvidas na prática do Direito Sanitário, paralelamente à discussão teórico-filosófica sobre o alcance do direito à saúde no começo do novo milênio.

Alguns integrantes desse grupo foram mais corajosos e tomaram a dianteira, registrando o domínio na Biblioteca Nacional. Era chegado o momento de tornar realidade a Revista de Direito Sanitário, patrocinada pelo Núcleo de Pesquisa em Direito Sanitário da Universidade de São Paulo (NAP-DISA/USP), vinculado organicamente a suas faculdades de Direito e de Saúde Pública.

Construímos um Conselho Editorial representativo do que havia de melhor na sociedade, nos serviços e na academia, no Brasil e no exterior, e começamos a trabalhar. Inicialmente, buscamos uma parceria com um grupo editorial, a Editora Revista dos Tribunais, que assegurou a confecção da publicação e sua distribuição durante uma década. Já mais amadurecido, em 2009 o próprio NAP-DISA/USP assumiu todas as tarefas de produção da Revista. Nessa época, foi reforçada a busca pela indexação nas mais relevantes bases de dados internacionais. E as conquistas foram se sucedendo lentamente, porém com segurança.

Hoje estamos certos de que a Revista é um importante veículo para a divulgação de temas do Direito Sanitário e para a discussão acadêmica da mais alta qualidade, contribuindo decisivamente para a formação dos profissionais que atuam no campo, a partir seja do direito, seja de qualquer das várias disciplinas que conformam a saúde pública.

Ao longo dos anos, a Revista de Direito Sanitário registrou em suas páginas os diversos fenômenos relacionados com a efetivação do direito à saúde no Brasil e no mundo, constituindo-se uma publicação científica de alto impacto no debate sobre temas estratégicos para o desenvolvimento do sistema de saúde brasileiro e para a plena efetivação do direito à saúde no Brasil.

A Revista é hoje um veículo de comunicação científica bastante eficaz e dinâmico, no qual se podem discutir, de forma ampla, plural, transparente e aprofundada, os principais aspectos que cercam a concepção da saúde como direito humano fundamental, 
tais como a judicialização da saúde pública e privada; a incorporação crescente e veloz de novas tecnologias de saúde ao sistema de saúde nacional; a consolidação e o crescimento do setor privado de saúde em seus diferentes mercados (medicamentos, alimentos, suplementos alimentares, cosméticos, saneantes, planos de saúde etc.); a implantação de um aparato jurídico-institucional no Estado brasileiro para responder ao dever expresso no artigo 196 da Constituição Federal de 1988; a normatização de políticas públicas; a proteção jurídica de um financiamento público adequado para o Sistema Único de Saúde (SUS); a aplicação dos princípios dos direitos humanos e da ética na regulação de pesquisas e serviços de saúde; dentre outros.

As complexidades verificadas para a plena realização do direito à saúde vêm exigindo dos diversos profissionais que atuam no sistema de saúde brasileiro (profissionais da saúde, da administração pública, do direito e das diversas áreas que compõem a saúde pública), um conhecimento cada vez maior do Direito Sanitário. O aumento de profissionais e acadêmicos interessados no tema resultou na consolidação de um conjunto relevante de pessoas que vêm pensando sobre como tornar mais eficaz e efetiva a regulação sanitária do país.

Testemunha da evolução deste campo do conhecimento científico no Brasil e passados 20 anos, a Revista de Direito Sanitário renova seu corpo editorial, incorporando novos colaboradores, profissionais e acadêmicos de universidades de todas as regiões do país e de importantes instituições estrangeiras com as quais o NAP-DISA/USP vem consolidando parcerias acadêmicas ao longo das últimas décadas.

Aos colaboradores históricos da Revista, agradecemos o apoio e a parceria durante todos esses anos e esperamos continuar dialogando sobre o Direito Sanitário nas páginas da publicação e nas atividades acadêmicas desenvolvidas pelo NAP-DISA/USP.

Aos novos colaboradores, damos as boas-vindas, certos de que muito contribuirão para que a Revista de Direito Sanitário continue sendo um instrumento de divulgação científica de excelência no campo do Direito Sanitário.

Aos nossos leitores, esperamos continuar oferecendo o que há de mais atual e relevante no desenvolvimento científico do Direito Sanitário. Sabemos que os desafios colocados nos tempos atuais, especialmente no que se refere à consolidação dos direitos sociais nos Estados Democráticos de Direito, são enormes; mas sabemos também que, juntos, seguiremos orientando nossos esforços para a promoção do desenvolvimento social, econômico e ambiental do Brasil, voltado à justiça social e à plena realização do direito humano universal à saúde.

Sueli Gandolfi Dallari

Primeira editora científica da Revista de Direito Sanitário Fernando Aith

Editor-Chefe da Revista de Direito Sanitário 